\title{
Urine Creatinine Measurement
}

National Cancer Institute

\section{Source}

National Cancer Institute. Urine Creatinine Measurement. NCI Thesaurus. Code C61048.

A quantitative measurement of the total amount of creatinine present in a sample of urine. 